\title{
PERENCANAAN STRUKTUR BAJA PADA KONSTRUKSI EMPAT LANTAI PADA HOTEL JAYA BAYA
}

\author{
${ }^{1 *}$ Alfin Azis Saputra, ${ }^{2}$ Sigit Winarto, ${ }^{3}$ Ahmad Ridwan \\ Fakultas Teknik Universitas Kadiri \\ e-mail: ${ }^{1 *}$ alfinaziz@gmail.com,${ }^{2}$ sigit.winarto@unik-kediri.ac.id,${ }^{3}$ ahmad ridwan@unik- \\ kediri.ac.id
}

\begin{abstract}
Construction buildings in Kediri area still tends to use concrete construction with conventional methods, which are prone to specifications from planning the structure of the building. Due the process of making cast dough and casting it is often not done properly so it can eliminate the strength and structure. Therefore, hotel building is planned to use Steel Construction and Precast Floor Elimination, in order to have not reduction in specification design structure. In LRFD method, probability analysis is not needed, except for general situations not set in Regulations Obtained LRFD planning calculations referring to the latest SNI 1729-2015. Based on the planning, the calculation structure of loading is calculated in $\mathrm{m}^{2}$, where the production results are entered into the Sap $2000 \mathrm{v} 20$ analysis software program. The structure used on PL 125 floor panels. 2000, beam WF 300x150x6.5x9, column WF 400x400z13x21, the conclusion of the structure is safe based on the applicable conditions.
\end{abstract}

Keywords $\quad$ : Steel Structure, LRFD, SNI 1729-2015, Planning

\begin{abstract}
Abstrak
Konstruksi bangunan di wilayah Kediri masih cenderung menggunakan konstruksi beton dengan metode konvensional, yang rentan terhadap spesifikasi dari perencanaan struktur bangunan. Karena proses pembuatan adonan gips dan casting itu sering tidak dilakukan dengan benar sehingga dapat menghilangkan kekuatan dan struktur. Oleh karena itu, bangunan hotel direncanakan menggunakan Konstruksi Baja dan Penghapusan Lantai Pracetak, agar tidak mengurangi struktur desain spesifikasi. Dalam metode LRFD, analisis probabilitas tidak diperlukan, kecuali untuk situasi umum yang tidak diatur dalam Peraturan yang Diperoleh Perhitungan perencanaan LRFD mengacu pada SNI 1729-2015 terbaru. Berdasarkan perencanaan, struktur perhitungan pemuatan dihitung dalam $\mathrm{m} 2$, di mana hasil produksi dimasukkan ke dalam program perangkat lunak analisis Sap 2000 v20. Struktur yang digunakan pada panel lantai PL 125. 2000, balok WF 300x150x6.5x9, kolom WF 400x400z13x21, kesimpulan struktur aman berdasarkan kondisi yang berlaku.
\end{abstract}

Kata Kunci : Struktur Baja, LRFD, SNI 1729-2015, Perencanaan 


\section{PENDAHULUAN}

Pada jaman yang modern ini pembangunan sangat pesat di berbagai daerah. Pembangunan gedung - gedung tinggi dan besar banyak dibangun didaerah - daerah dengan tingkat penduduk yang tinggi serta kegiatan ekonominya pesat[1]. Hal ini disebabkan oleh semakin banyaknya makhluk hidup yang ada namun lahan yang digunakan kurang, sehingga bangunan yang tinggi menjadi salah satu alternatife untuk mengurangi atau menghemat lahan yang ada. Hal tersebut mendorong para perencana bangunan untuk membuat sebuah bangunan tingkat tinggi yang aman dan tahan terhadap gempa[2][3].

Akhir - akhir ini gempa yang mengguncang Indonesia terjadi dalam skala besar, tahun 2004, tercatat tiga gempa besar di indonesia yaitu di kepulauan Alor (11 Nov. Skala 7.5), gempa Papua (26 Nov. Skala 7.1) dan gempa Aceh (26 Des. Skala 9.2) yang disertai Tsunami, dan gempa gempa lainnya yang masih sering terjadi hingga saat ini, sehingga mengakibatkan kerusakan pada bangunan tingkat tinggi yang cukup parah. Kondisi itu menyadarkan kita, bahwa Indonesia merupakan daerah rawan terjadinya gempa. Untuk mengurangi resiko bencana yang terjadi diperlukan konstruksi bangunan tahan gempa. Hal ini pula yang menuntut seorang perencana agar membuat perencanaan struktur bangunan tingkat tinggi agar dapat menahan gaya yang diakibatkan oleh gempa bumi tersebut[4][5][6].

Pembangunan gedung di daerah Kediri saat ini masih cenderung menggunakan konstruksi beton dengan metode konvensional, yang rawan sekali melenceng dengan spesifikasi dari perencanaan struktur gedung tersebut. Dikarenakan proses pembuatan adonan cor dan pelaksanaan pengecoran sering kali tidak dilakukan dengan baik seingga dapat mengurangi kekuatan dari struktur tersebut. Maka dari itu bangunan Hotel ini di rencanakan menggunakan Konstruksi Baja dan Panel Lantai Precast, supaya tidak ada pengurangan spek dari desain perencanaan struktur[5][6][9].

\section{METODOLOGI PERENCANAAN}

\subsection{Perencanaan}

A. Spesifikasi dan Dara Struktur.

1) Model Struktur direncanakan terleta di kediri, wilayah gempa zona 4 pada jenis tanah sedang.

2) Gedung terdiri dari 4 (empat) lantai dan berfungsi sebagai hotel dengan beban hidup $250 \mathrm{~kg} / \mathrm{m}^{2}$ (PPIUG 1983). 
3) Lantai Gedung menggunakan beton precast yang kuat menerima beban sampai $405 \mathrm{~kg} / \mathrm{cm}$

4) Struktur utama (balok dan kolom) menggunakan bahan baja, mutu BJ37

5) Denah Gedung terdiri dai 4 lantai yang mana lanatai 1 difungsikan sebagai resepsionis, loby, restouran, dan lantai 2,3,4 sebagai hotel, kantor dan ruang rapat, bentang balok arah $\mathrm{x}$ dengan bentang terbesar adalah 8 meter, dan balok arah $\mathrm{y}$ memiliki bentang terbesar adalah 8 meter.

B. Metode Perencanaan.

Tahapan Perencanaan.

Suatu perenanaan harus dilakaukan dengan sistematika yang jelas dan teratur sehingga hasilnya dapat dipertanggungjawabkan. Oleh karena itu perencanaan ini dibagi menjadi beberapa tahapan yaitu:

1) Tahap $I$

Tahap persiapan. Persiapan dilakukan untuk mencari data dan informasi yang mendukung perencanaan struktur.

2) Tahap II

Pemilihan profil baja untuk elemen utama struktur (balok, balok anak, dan kolom)

3) Tahap III

Perencanaan pelat atap dan pelat lantai precast dengan menentukan panel lantai precast yang memiliki spesifikasi struktur aman berdasarkan batas layan, dan perencanaan tangga.

4) Tahap IV

Pemodelan geometri struktur portal sebagai sarana perhitungan pembebanan dan analisa pada program SAP2000[10].

5) Tahap V

Analisa struktur terhadap model struktur dengan bantuan software SAP2000 V20 untuk mengetahui besarnya nilai joint displacement, momen, gaya geser, dan gaya tekan atau gaya tarik pada strutur portal terhadap beban yang bekerja (beban luar dan beban gravitasi).

\subsection{Perencanaan Struktur Secara Luas}

Pada perencanaan suatu konstruksi bangunan gedung diperlukan beberapa landasan teori berupa analisa struktur, ilmu tentang kekuatan bahan serta hal lain yang berpedoman pada peraturan-peraturan yang berlaku di Indonesia[11]. Ilmu teoritis diatas tidaklah cukup karena analisa secara teoritis tersebut hanya berlaku pada kondisi struktur yang ideal sedangkan gayagaya yang dihitung hanya merupakan pendekatan dari keadaan yang sebenarnya atau yang 
diharapkan terjadi. Perencanaan adalah bagian yang penting dari pembangunan suatu gedung atau bangunan lainnya[12][13]. Survey dan penyelidikan tanah merupakan tahap awal dari proyek. Perencanaan dari suatu konstruksi bangunan harus memenuhi berbagai syarat konstruksi yang telah ditentukan yaitu kuat, kaku, bentuk yang serasi dan dapat dilaksanakan dengan biaya yang ekonomis tetapi tidak mengurangi mutu bangunan tersebut, sehingga dapat digunakan sebagaimana fungsinya[14][15]. Perencanaan Struktur bisa didefinisikan sebagai perpaduan antara seni dan ilmu pengetahuan yang dikombinaksikan dengan kemampuan seorang ahli struktur mengenai prilaku struktur dengan dasar-dasar pengetahuan dalam statiks, dianmika, mekanika bahan, dan analisa struktur, untuk menghasilkan suatu struktur yang ekonomis dan aman, selama masa layannya[16][17][18].

\subsection{Konsep Dasar LRFD}

Dua filosofi yang sering digunakan dalam perencanaan struktur baja adalah perencanaan berdasarkan tegangan kerja/working stress design (Alloweble Stress Design/ASD) dan perencanaan kondisi batas limit states design (Load and Resistance Factor Design/LRFD). Metode ASD dalam perencanaan struktur baja telah digunakan dalam kurun waktu kurang lebih 100 tahun, dan dalam 20 tahun terahir prinsip perencanaan struktur baja mulai beralih ke konsep LRFD yang jauh lebih rasional dengan berdasarkan pada konsep probabilitas. Dalam metode LRFD tidak diperlukan analisa probabilitas secara penuh, terkecuali untuk situasi-situasi tisak umum yang tidak diatur dalam peraturan[19][20][21].

LRFD (Load And Resistance Factor Deisgn) adalah spesifikasi yang dikeluarkan oleh AISC (America Instate Of Steel Construction) untuk desain konstruksi baja, berdasarkan ketahanan metode kekuatan ultimit (Metode Plastis)[22][23]. LRFD memberikan perbandingan yang lebih spesifik antara beban $\mathrm{Q}$ dan resistensi $\mathrm{Rn}$, seperti persamaan untuk persyaratan mendapatkan keamanan sebagai berikut:

$\phi \mathrm{Rn}=\sum \gamma \mathrm{i} \mathrm{Qi}$

Di mana ruas kiri mewakili resistensi (kekuatan) dari komponen atau sistem, sedangkan ruas kanan mewakili beban yang diharapkan akan ditanggung sehingga cenderung memberikan struktur yang lebih aman, Pada sisi kekuatan harga nominasi resistensi Rn dikalikan dengan faktor resistensi (reduksi kekuatan) $\phi$ untuk mendapatkan kekuatan desain. Pada sisi beban berbagai efek beban Qi (seperti beban mati, beban hidup, dan beban salju) dikalikan dengan faktor-faktor kelebihan beban $\gamma \mathrm{i}$ untuk mendapatkan jumlah $\sum$ yi Qi dari beban-beban terfaktor. LRFD (Load And Resistance Factor Design) adalah suatu metode dalam perencanaan bangunan gedung yang memperhitungkan faktor beban dan faktor ketahanan material. Konsep desain ini pada prinsipnya tegangan yang terjadi dalam setiap elemen struktur harus lebih kecil dari 
tegangan yang di ijinkan. Dengan pengertian lain, beban yang bekerja harus lebih kecil dari kapasitas kekuatan elemen dibagi dengan suatu faktor keamanan safety factor.

\subsection{Konsep Dasar Perencanaan.}

A. Gaya Akibat Beban Gravitasi

1) Beban Mati

Beban mati adalah berat seluruh bahan konstruksi bangunan gedung yang terpasang, termasuk dinding, lantai, atap, plafond, tangga, dinding partisi tetap, finishing, klading gedung dan komponen arsitektur dan struktur lainnya serta peralatan layan terpasang lain termasuk berat keran (SNI-1726-2013).

Tabel 1. Berat Sendiri Struktur Gedung

\begin{tabular}{|c|l|c|c|}
\hline No & \multicolumn{1}{|c|}{ Jenis Beban Mati } & Berat & Satuan \\
\hline 1 & Baja & 7850 & $\mathrm{~kg} / \mathrm{m}^{3}$ \\
\hline 2 & Beton bertulang & 2400 & $\mathrm{~kg} / \mathrm{m}^{3}$ \\
\hline 3 & Panel lantai precast & 780 & $\mathrm{~kg} / \mathrm{m}^{3}$ \\
\hline
\end{tabular}

Sumber: Peraturan Pembebanan Indonesia Untuk Gedung 1983

Tabel 2. Berat Sendiri Komponen Gedung

\begin{tabular}{|l|l|c|c|}
\hline No & \multicolumn{1}{|c|}{ Jenis Beban Mati } & Berat & Satuan \\
\hline 1 & Adukan semen, per cm tebal & 21 & $\mathrm{Kg} / \mathrm{m}^{2}$ \\
\hline 2 & Pasangan dinding mata merah 1/2 bata & 250 & $\mathrm{Kg} / \mathrm{m}^{2}$ \\
\hline 3 & Plafond (langit-langit) & 11 & $\mathrm{Kg} / \mathrm{m}^{2}$ \\
\hline 4 & Penggantung langit-langit & 7 & $\mathrm{Kg} / \mathrm{m}^{2}$ \\
\hline 5 & Penutup lantai keramik & 24 & $\mathrm{Kg} / \mathrm{m}^{2}$ \\
\hline 6 & Pasangan dinding bata ringan tbl 15cm & 60 & $\mathrm{Kg} / \mathrm{m}^{2}$ \\
\hline 7 & Instalasi listrik, AC, dan plumbing (MEP) & 25 & $\mathrm{Kg} / \mathrm{m}^{2}$ \\
\hline
\end{tabular}

Sumber: Peraturan Pembebanan Indonesia Untuk Gedung 1983

2) Beban Hidup

Beban hidup adalah semua beban yang diakibatkan oleh pengguna dan penghuni bangunan gedung atau struktur lain yang tidak termasuk beban konstruksi dan beban lingkungan, seperti beban angin, beban hujan, beban gempa, beban banjir, atau beban mati. (SNI-1727-2013). 
Tabel 3. Beban hidup pada lantai bangunan

\begin{tabular}{|l|l|c|c|}
\hline \multirow{2}{*}{ No } & \multicolumn{1}{|c|}{ Jenis Beban Hidup Pada Lantai Bangunan } & Berat & Satuan \\
\hline 1 & Lantai hotel, asrama, dan rumah sakit & 250 & $\mathrm{Kg} / \mathrm{m}^{2}$ \\
2 & Dak atap & 125 & $\mathrm{Kg} / \mathrm{m}^{2}$ \\
3 & Tangga dan bordes & 300 & $\mathrm{Kg} / \mathrm{m}^{2}$ \\
\hline
\end{tabular}

Sumber: Peraturan Pembebanan Indonesia Untuk Gedung 1983

3) Beban Angin

Beban angin adalah beban yang bekerja pada struktur akibat tekanan-tekanan dari gerakan angin[24]. Beban angin sangat tergantung dari lokasi kegiatan dari struktur. Besarnya tekanan tiup harus diambil minimum sebesar $25 \mathrm{~kg} / \mathrm{m} 2$.

B. Perencanaan Kapasitas.

Struktur gedung harus memenuhi persyaratan "kolom kuat balok lemah", artinya ketika struktur gedung memikul pengaruh Gempa rencana, sendi sendi plastis di dalam struktur gedung tersebut hanya boleh terjadi pada ujung ujung balok dan pada kaki kolom dan kaki dinding geser saja. Implementasi persyaratan ini didalam perencanaan struktur beton dan struktur baja ditetapkan dalam standar beton dan standar baja yang berlaku.

\section{Wilayah Gempa}

Indonesia ditetapkan terbagi dalam 6 wilayah gempa, dimana wilayah wilayah gempa adalah wilayah dengan kegempaan paling rendah dan wilayah gempa 6 dengan kegempaan paling tinggi. Pembagian wilayah gempa ini didasarkan atas percepatan puncak batuan dasar akibat pengaruh gempa rencana dengan periode ulang 500 tahun, yang nilai rata-ratanya untuyk setiap wilayah gempa ditetapkan dalam SNI 1726-2002.

D. Perencanaan Struktur

\section{1) Perencanaan Pelat}

Dalam perencanaan plat, perencana ingin menerapkan penggunaan panel lantai sebagai trobosan alternatif dimana plat lantai tidak dicor secara konvensional, tetapi menggunakan cara yang lebih efisien yaitu langsung pemasangan. Pelat lantai precast yang digunakan yaitu panel lantai PL 125. 2000 yang memiliki dimensi panjang bersih 1970mm, lebar bersih $600 \mathrm{~mm}$, dan tebal $125 \mathrm{~mm}$. Dari spesifikasi dan hasil tes uji maka dapat digunakan acuan kontrol terhadap plat lantai yang digunakan.

2) Desain LRFD Struktur Baja 
Pada desain kolom dan balok menggunakan desain LRFD. Secara umum, struktur dinyatakan aman apabila memenuhi persyaratan berikut: $\phi R>\Sigma$ yi.Qi Bagian kiri dari persamaan tersebut mempresentasikan tahanan atau kekuatan dari sebuah komponen atau sistem struktur, dan bagian kanan persamaan menyatakan beban yang harus dipikul struktur tersebut. Jika tahanan nominal Rn dikalikan dengan suatu faktor $\phi$ maka akan diperoleh tahanan rencana. Namun demikian, berbagai macam beban (beban mati, beban hidup, beban gempa dan lain lain) pada bagian kanan persamaan diatas dikalikan faktor beban yi untuk mendapatkan jumlah beban terfktor ( $\Sigma$ yi.Qi.).

\subsection{Analisa Program Sap2000}

A. Metode Input SAP2000 V20.

Secara umum, urutan input dalam sap2000 dapat dibagi menjadi beberapa bagian yaitu:

1) Membuka aplikasi analisa SAP2000 V20

2) Memilih file baru (new file)

3) Menentukan unit satuan sebelum menginputkan sesuatu dimensi/beban

4) Membuat model struktur untuk mendesain geometri struktur portal dengan menginputkan jumlah dan jarak antar gride untuk sumbu $\mathrm{x}, \mathrm{y}, \mathrm{z}$

5) Mendefinisikan material yang dipakai (Define-Material)

6) Mendefinisikan profil struktur yang dipakai (Define-Section Proprtis-Frame Section)

7) Mendefinisikan pelat struktur yang dipakai (Define-Section Proprtis-Area Section)

8) Mengaplikasikan profil yang digunakan.

9) Mendefinisikan beban dan kombinasi pembebanan (Define-Load)

10) Pengaplikasian pembebanan

11) Menganalisa hasil input (Run Analisis)

12) Mengecek hasil.

\section{HASIL DAN PEMBAHASAN}

A) Perhitungan pembebanan dihitung dalam $\mathrm{m}^{2}$., dari volume $\mathrm{m}^{2}$ yang didapat dikalikan dengan berat jenis material sesuai peraturan pembebanan yang ada (PPIUG 1983) yang mana hasil pembebanan dimasukan ke dalam program shofware analisa sap 2000 v20.

B) Didapatkan perhitungan perencanaan LRFD yang mengacu pada SNI terbaru 03-129-2015 
C) Dalam menganalisa perhitungan struktur menggunakan software SAP2000 V20, outputnya bisa digunakan untuk data perhitungan kontrol sesuai dengan peraturan yang ada, hasil kontrol sebagai berikut:

Perencanaan plat lantai lebih mudah karena spesifikasi didukung dengan data tes uji yang dilakukan oleh pabrik sehingga data tersebut bisa digunakan untuk acuan perencanaan.

Kontrol: beban rencana $<$ beban imposed $\rightarrow 299<405 \mathrm{~kg} / \mathrm{m}^{2}$

Aman (OK)

Kontrol: P rencana $<\mathrm{P}$ hasil tes $\rightarrow 352.64<2380.00$

Aman $(\mathrm{OK})$

Balok struktur baja direncanakan dengan profil baja WF 300x150x6.5x9 dengan hasil kontrol tahanan momen lentur $\mathrm{Mu}<\phi b * \mathrm{Mn} \rightarrow 85418754<14285600$

Aman (OK),

tahanan geser $\mathrm{Vu}<\phi \mathrm{f} * \mathrm{Vn} \rightarrow 210600<280800$

Aman (OK),

interaksi geser dan lentur $0.90625<1.375$

Aman (OK),

disimpulkan Aman sesuai SNI 03-1729-2015

Kolom struktur baja direncanakan dengan profil baja WF 400x400x13×21 dengan hasil kontrol interaksi aksial tekan dan momen lentur $0.46<1.0$

Aman (OK), tahanan geser $37378.59<561600$

Aman (OK),

interaksi geser dan lentur $0.472<1.375$

Aman (OK),

disimpulkan Aman sesuai SNI 03-1729-2015

Sambungan balok-kolom baut tipe A-325 dengan 2 baris dengan jumlah 7 baut perbaris diperoleh dari hasil perhitungan gaya tarik pada baut $91195.60<93258$

Aman (OK),

gaya geser pada baut $2670<49738$

Aman (OK),

gaya tumpu pada baut $2670<106560$

Aman (OK),

kombinasi gaya tarik pada baut $13.29<247.5$

Aman (OK),

disimpulkan disimpulkan Aman sesuai SNI 03-1729-2015

Sambungan balok-balok dengan baut tipe A-325 dengan jumlah 16 baut pada badan dan 8 pada masing masing sayap, diperoleh hasil jumla baut pada badan $1<8$ Aman (OK), tebal plat sambung pada badan $1.207<10$ Aman (OK),

jumlah baut pada sayap $1<8$ Aman (OK), tebal plat sambung pada sayap $3.89<10$ Aman (OK), kekuatan baut pada badan terhadap geser $24553<76160.7$ Aman (OK), kekuatan baut pada badan terhadap tumpu $24553<60606$ Aman (OK), disimpulkan Aman sesuai SNI 03-1729-2015 


\section{KESIMPULAN}

1) Dalam hal perencanaan dan perancangan struktur alangkah baiknya memahami dahulu peraturan-peraturan yang berlaku khususnya SNI 03-1729-2015 mengenai Tata Cara Perencanaan Struktur Baja Untuk Gedung.

2) Untuk pemrograman, dan pengoprasian SAP2000 V20, dalam penginputan data sebelum dianalisa alangkah baiknya di cek kembali supaya data outputnya dapat dikontrol secara manual.

\section{SARAN}

Dari hasil perhitungan perencanaan struktur baja pada konstruksi empat lantai pada hotel jaya baya diatas penulis memberikan saran sebagai berikut:

1. Supaya lebih mudah proses menghitung diperlukan persiapan dengan memperoleh data teknis yang lengkap, dimana data tersebut nantinya akan sangat menunjang dalam membuat rencana analisa perhitungan, sesuai dengan standar dan syarat-syaratnya.

2. Agar mudah,cepat dan hasil yang akurat proses menghitung baiknya menggunakan aplikasi Microsoft Excel.

\section{UCAPAN TERIMA KASIH}

Dalam penyusunan artikel ini, penulis ucapkan terimakasih kepada dosen pembimbing dan Universitas Kadiri. Penulis berharap agar artikel ini dapat bermanfaat bagi pembaca.

\section{DAFTAR PUSTAKA}

[1] A. Kaprina, S. Winarto, and Y. Cahyo, "ANALISA PRODUKTIFITAS ALAT BERAT PADA PROYEK PEMBANGUNAN GEDUNG FAKULTAS SYARIAH DAN ILMU HUKUM IAIN TULUNGANGUNG," Jurmateks, vol. 1, no. 1, pp. 1-11, 2018.

[2] W. Dewobroto, "Perancangan balok beton bertulang dengan SAP 2000," 2013.

[3] G. H. Cahyo, "Perhitungan perencanaan Struktur Gedung Beton bertulang Di Jalan Ahmad Yani Pontianak.” Tanjungpura University, 2010.

[4] I. W. Suasira, I. M. S. Kader, and I. M. Jaya, "Perbandingan Desain Struktur Beton Bertulang yang Dibebani Dinding Pasangan Bata Merah Dengan Bata Ringan Dengan Menggunakan Program SAP 2000," Log. J. Ranc. Bangun dan Teknol., vol. 16, no. 2, p. 126, 2017.

[5] A. Dolu and H. Hasan, "Metode Elemen Hingga Dengan Program Matlab dan Aplikasi 
Sap 2000 Untuk Analisis Struktur Cangkang," SMARTek, vol. 8, no. 2, 2010.

[6] A. I. Candra, A. Yusuf, and A. R. F, "Studi Analisis Daya Dukung Pondasi Tiang Pada Pembangunan Gedung Lp3m Universitas Kadiri,” CIVILLa, vol. 3, no. 2, pp. 166-171, 2018.

[7] J. S. Muda, M. S. Gumilar, and F. Dhiniati, "Perencanaan Struktur Gedung Kantor Dishub Kota Pagar Alam Berbasis Program SAP 2000,” J. Ilm. BERING'S, vol. 4, no. 02, pp. 51-67, 2017.

[8] F. Faizah, "EVALUASI KINERJA STRUKTUR BETON DENGAN ANALISIS PUSHOVER PADA GEDUNG CIPTA KARYA TATA RUANG DAN KEBERSIHAN KABUPATEN PACITAN MENGGUNAKAN PROGRAM SAP 2000,” $J$. KONTRUKSI, vol. 2, no. 1, 2014.

[9] I. Hidayat, M. Suangga, F. Leonardo, and G. Juliastuti, “THE COMPARISON OF SLAB DEFLECTION BASED ON FIELD MEASUREMENT, MANUAL CALCULATION (LEVY METHOD) AND FINITE ELEMENT METHOD (PROGRAM SAP 2000),” J. Teknol., vol. 78, no. 5, 2016.

[10] N. A. Setiyowati, B. Suswanto, and R. Soewardojo, "Studi Perbandingan Perilaku Profil Baja WF dan HSS Sebagai Bresing pada SCBF Akibat Beban Lateral dengan Program Bantu Finite Element Analysis," J. Tek. ITS, vol. 1, no. 1, pp. D40-D45, 2012.

[11] J. Galanthe, "PERHITUNGAN STRUKTUR GEDUNG RUKO 3 LANTAI JALAN DI PANJAITAN DENGAN MENGGUNAKAN METODE TAKABEYA DAN PROGRAM SAP 2000,” KURVA S J. Mhs., vol. 4, no. 1, pp. 602-608, 2015.

[12] F. Ramdhani, "PELATIHAN PENGGUNAAN SOFWARE STRUCTURAL ANALYSIS PROGRAM (SAP) PADA STRUKTUR BANGUNAN GEDUNG DI SEKOLAH MENENGAH KEJURUAN NEGERI 2 DUMAI,” J. Pengabdi. Masy. Multidisiplin, vol. 1, no. 1, pp. 72-80, 2017.

[13] P. Lumba, "ANALISIS BANGUNAN TIDAK SIMETRIS DALAM MEMIKUL GAYA GEMPA DENGAN MENGGUNAKAN SAP 2000,” J. APTEK, vol. 2, no. 1, pp. 72-77, 2014.

[14] W. Apriani, "Pelatihan SAP 2000 Dalam Perencanaan Konstruksi Gedung Beton Bertulang Dan Baja Tahan Gempa Berdasarkan Sni 03-1726-2012," Padang. Pros. Konf. Nas. PKM CSR ke, vol. 2, 2016.

[15] B. Mardiyanto, "Studi Perilaku Pelat Beton Di Atas Tanah Dengan Metode Elemen Hingga (Sap 2000 V. 11.0. 0) Ditinjau Pada Variasi Modulus Reaksi Subgrade (Kv) dan Mutu Pelat Beton,” 2010. 
[16] N. Pertiwi, "PENERAPAN APLIKASI SAP2000 PADA MATA KULIAH STRUKTUR BETON GEDUNG MELALUI METODE PELATIHAN PADA MAHASISWA PTSP FT UNM,” J. MEKOM (Media Komun. Pendidik. Kejuruan), vol. 3, no. 2, 2016.

[17] A. S. Dermawan and D. Yuniar, "ANALISIS STRUKTUR PORTAL GUDANG KARET MENGGUNAKAN SAP 2000,” Polhasains J. sains dan Terap. Politek. Hasnur., vol. 3, no. 02, pp. 1-7, 2015.

[18] A. I. Candra and E. Siswanto, "Rekayasa Job Mix Beton Ringan Menggunakan Hydroton dan Master Ease 5010," CIVILLa, vol. 3, no. 2, pp. 162-165, 2018.

[19] Y. A. Adhitama, E. Purwanto, and A. Supriyadi, "Analisis Kinerja Gedung Bertingkat Berdasarkan Eksentrisitas Lay Out Dinding Geser Terhadap Pusat Massa Dengan Metode Pushover," Matriks Tek. Sipil, vol. 4, no. 1, 2016.

[20] J. S. Muda, M. S. Gumilar, and V. Iteridi, "PERENCANAAN STRUKTUR GEDUNG BARU KANTOR DISHUB KOTA PAGAR ALAM 4 LANTAI BERBASIS PROGRAM SAP 2000,” J. Berings, vol. 6, no. 2, pp. 26-31, 2017.

[21] F. Aribisma, I. G. P. Raka, and T. Tavio, "Evaluasi Gedung MNC Tower Menggunakan SNI 03-1726-2012 dengan Metode Pushover Analysis,” J. Tek. ITS, vol. 4, no. 1, pp. D71-D75, 2015.

[22] I. Widiasanti and S. Musalamah, "PERBANDINGAN BERAT KUDA-KUDA BAJA ATAP LIMAS MENGGUNAKAN APLIKASI SAP 2000 â€“ 2 DIMENSI DENGAN 3 DIMENSI," J. Menara, vol. 5, no. 1, p. 15, 2010.

[23] E. K. Pangestuti, R. K. Kusumawardani, A. Priaji, and D. L. Nikmah, "Perbandingan Analisa Perhitungan Beton Struktural pada Proyek Pembangunan Gedung F Universitas Pekalongan," J. Tek. Sipil dan Perenc., vol. 18, no. 2, pp. 159-164, 2016.

[24] T. Y. Purnomo, L. D. Krisnawati, and Y. C. S. Purnomo, "Kajian Jembatan Kecamatan Sendang (Ruas Jalan Tugu-Pabyongan) Kabupaten Tulungagung dengan Metode Komposit,” J. Manaj. Teknol. Tek. Sipil, vol. 1, no. 1, pp. 112-125, 2018, doi: 10.30737/jurmateks.v1i1.145. 